\title{
Combining Distance and Traditional Learning: A Study of the Use of Virtual Learning Environment Objects and Massive Online Open Courses in Statistics Class
}

\author{
Silvio Carvalho Neto
}

\begin{abstract}
This paper presents a discussion about the use of Massive Online Open Courses (MOOC) and Virtual Learning Environment (VLE) objects in statistics class. The objective is to discuss possibilities to improve the learning process of statistics content by students combining distance and traditional learning. Professors can use virtual objects such as video, audio, text files, links and other materials to help students to understand better most statistical subjects outside the classroom. The purpose of this paper is to report an innovative educational experience about teaching statistics in engineering undergraduate courses using a VLE. The research is qualitative, bibliographic and web-based. Results of a survey and informal interviews with engineering students suggest what issues are relevant to teach statistics in traditional courses using a pedagogical hybrid format.
\end{abstract}

Index Terms-Massive online open courses, virtual learning environments, statistics.

\section{INTRODUCTION}

Statistics is everywhere. They are part of everyday life of most people. It is possible to consider statistics as a branch of mathematics field. Statistical knowledge should be in the general culture of any person when faced with almost everyday facts. In scientific research and knowledge production, learning statistics is not only an interesting option but also a crucial issue to be understood.

Statistics is one of the pillars of scientific research. In some fields, such as business and engineering, the discipline, and its statistical concepts are fundamental to different applications and research techniques. Due its importance to science, we believe it is crucial to improving didactic and practical methods of teaching statistics.

Thus, this research seeks to identify characteristics of the processes of teaching statistics based on distance educational paradigm. We look for new ways to blend distance and traditional education, using online objects to help students to learn the concepts acquired in their regular statistics classes.

This study presents the results of a survey and informal interviews made with engineering students enrolled in statistics classes. Results reveal the importance of some Massive Open Online Courses (MOOC) and virtual learning objects, such as video, audio, text files, links and other online materials, in statistical subjects.

Manuscript received June 30, 2015; revised October 13, 2015. This work was supported by Uni-FACEF Centro Universitário Municipal de Franca-SP-Brazil.

C. N. Silvio is with Centro Universitário Municipal de Franca, Brazil (e-mail: silviocarvalhoneto@gmail.com).
This innovative educational experience, using Virtual Learning Environment (VLE) and the possibility to integrate traditional courses with massive online courses can be potentially a new successful way to teach statistical concepts effectively. The teaching process could be based essentially on practical exercises resolution with the VLE as support.

\section{RESEARCH METHOD}

The research is exploratory and qualitative. First steps of the research involved exploring the literature by bibliographic and documentary research. This initial exploratory research has the objective to understand concepts and definitions of Virtual Learning Environments and MOOC used in statistics courses. The research was web-based, browsing websites to find online platforms and massive courses specific involving statistical concepts, available in the first half of 2015.

The studied VLE is a single case study. This case presents a practical application of virtual objects in a learning environment online. Students from three engineering undergraduate courses in a Brazilian university located in São Paulo State compose the population of the survey. The survey population was 165 students from Production and Civil Engineering statistical classes. This study utilized the survey method to collect data. The students answered the questionnaire at the same time they were in a traditional class. The answer rate is $85 \%, 141$ students responded to the survey. Students are from two periods of civil engineering (one on daytime and one nocturnal) and one class of production engineering (nightly basis only). Table I shows the percentage of each period in the sample. Additional to the survey we did informal interviews with the students.

TABLE I: STUDENTS SAMPLE BY MAJOR AND PERIOD

\begin{tabular}{cccc}
\hline \hline Course & Daytime & Nightly & \\
\hline Civil Eng. & $43(30.5 \%)$ & $57(40.4 \%)$ & $100(70.9 \%)$ \\
Prod. Eng. & - & $41(29.1 \%)$ & $41(29.1 \%)$ \\
\hline & $43(30.5 \%)$ & $98(69.5 \%)$ & $141(100.0 \%)$ \\
\hline \hline
\end{tabular}

The variable measure used was a four-point Likert scale, from nothing/totally disagree (1) to excessive/ totally agree (4) to the proposed statement. The variables in the survey were: V1) Level of VLE usage during the course; V2) other Internet material usage level; V3) Online videos level of use; V4) motivation to learn using internet objects; V5) Learning assistance of materials available online; V6) Relevance of materials available online; V7) Learning performance with online materials. The analysis method is statistical, using descriptive statistics, as frequency, mean and standard 
deviation and bivariate Pearson correlation.

Informal interviews were the way used to capture feedback and the reasons students were (or not) accessing the VLE or using online materials. Interviews also brought forward reasons that could increase the level of usage of Internet materials in statistics classes.

\section{VIRTUAL LEARNING ENVIRONMENT TO SUPPORT STATISTICS TEACHING}

Virtual Learning Environments (VLE) are online information systems involving the online spread of teaching and learning objects. These systems are suitable for distributing online materials for communication and learning evaluation. The services provided by a VLE include monitoring the educational progress of the student. In addition to material delivery, VLE update learners profile with details of their activities and educational background. Through a virtual learning system, it is possible to a statistics professor to manage all the content available to students, as well as monitoring the progress of activities and exercises made by the student.

It is an interesting possibility to blend lectures and in classroom exercises with objects in virtual environments. VLE allows the professor to create a virtual community dedicated to the education process. Several modules compose virtual environments. They can support teaching tools as its resources are available online and allow the interaction between agents in a course or discipline.

The features offered by VLE strengthen learning concepts learned previously in real life classrooms [1]. The statistics virtual environment should have the same principle as the traditional teaching method in the classroom, using exercises and problem-based learning.

VLE support teacher- student communication, with several tutorials, support among peers, working groups and assessments. The main advantage of using a virtual environment to support classroom learning is that it organizes all features and information in a single location providing a unique identity to the student. It maintains asynchronous and synchronous communication channels of study. VLE provides support and resources to help students who do not have enough time to participate in all classroom activities.

Using a VLE the professor provides online materials, assigns tasks, makes notes to assessments and monitors the student performance in these online evaluations. Instructor and students can discuss and continue discussions between classes in various forms of communication, which allows individual and group discussion about the assessment.

With the VLE, the professor can create an area for students to store and share materials, and their files uploaded. The professor can view usage statistics, which identifies who use the system, what they access and when the students are accessing online objects.

Practical exercises in the classroom are time limited. If a VLE is used, this restriction disappears. Applying objects in the virtual environment the teacher can offer educational content, lists of extra exercises, maps the course content, and interact and evaluate these activities.Professors verify students achievement and give online support. This online communication with students is essentially fast.

VLE provide Internet links to external content. It is possible to find a large number of different VLE products available in the market. However, we note that not all VLE offer the same features. Learning environments on the web can be found as open source (General Public License - GLP) or proprietary. The GPL requires a community of developers since it allows the author freely distribute the system's source code so that other programmers can change and customize it according to specific needs. The benefits of open source systems are updated features, easy customization, data models, inflexible architectures, service and support of the developer community, and fast return on investment. These benefits and the characteristic of inter-communication with other applications, through standardization and the vision of the developer community, have made this type of system (open source) to be widely adopted by universities.

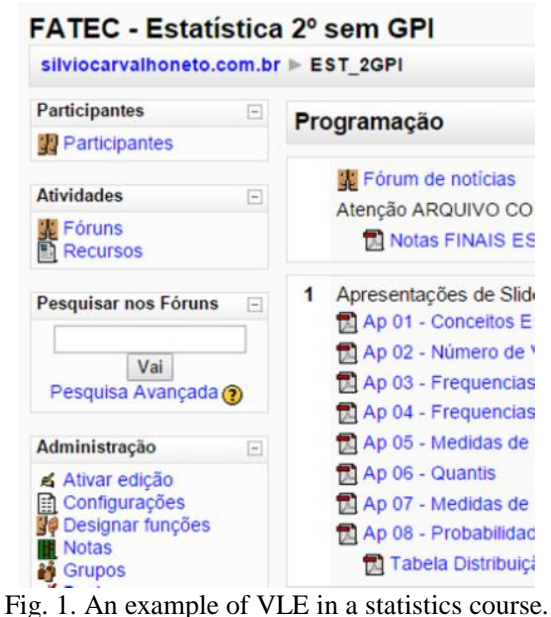

Moodle (Modular Object Oriented Development Learning Environment) is one of these open source systems that act as Virtual Learning Environment. Moodle is a highly used VLE in the world. Moodle is a cheap and efficient system applied in online education. We believe that Moodle is a viable, inexpensive and highly effective tool for teaching statistics, combining distance and traditional learning to share materials, links, provide extra content to the classroom and communicate with the students.

One VLE based Moodle was the virtual environment used in this study, available to the students, who later took the survey. The educational institution server hosts the system. It offers content texts, scientific articles, pdf files, slide presentations used in class and extra exercises with respective answers in Excel spreadsheets. Statistical concepts are suitable to be worked in spreadsheets, thus the contact of the student with files in Excel and those statistical equations placed as functions in spreadsheets, is crucial to the learning process of the whole statistical content.

The virtual environment also provides access to various external videos that complement lectures on each topic, such as documentaries on the history of statistics and practical application of statistics in real life, for example. The richest possibility of the virtual environment to support statistical teaching is the presence of links to external sources of consultation, and courses from other institutions and teachers.

Professors can complement all material available on VLE 
with links to external online courses, including the Massive Open Online Courses. Professors should stimulate students to take these online statistical courses content from other online institutions, to reinforce learned material in the classroom.

Fig. 1 presents a screenshot of the Virtual Environment object of this study, with an example of materials in pdf files and external links available to the students. The content is available in the Portuguese language, as is a Brazilian course. All participants can access grades and assessments results from the main course page.

\section{MOOCS FOR TEACHING STATISTICS}

The MOOCs are online learning environments distributing traditional universities courses openly to anyone connected to the Internet. They have the ability to spread knowledge in a mass way over the Internet. The technological environment in MOOCs is designed to support thousands of access at the same time. People from all over the world can attend massive online courses. In the case of MOOC, learning process adopts the logic of networks. It goes from the individual experience of a passive public receiving static information to become a collective and multi-directional experience [2].

The MOOCs are mostly based on video lessons, online quizzes and discussion forums. Students can take these lessons from some of the best universities in the world, for free, at the time and where they prefer. Massive courses spread knowledge through a whole online environment.

TABLE I: MOOCS FOR STATISTICS COURSES

\begin{tabular}{lll}
\hline \hline MOOC & Website & Main Language \\
\hline Udacity & www.udacity.com/ & English \\
Coursera & www.coursera.org/ & English \\
Saylor.Org & www.saylor.org/ & English \\
edX & www.edx.org/ & English \\
Khan Academy & www.khanacademy.org & English \\
Tarea Plus & www.tareasplus.com/ & Spanish \\
Miríada X & www.miriadax.net/ & Spanish \\
Veduca & www.veduca.com.br/ & Portuguese \\
\hline \hline
\end{tabular}

TABLE II: STATISTICAL LEARNING COMPONENTS IN THE KHAN ACADEMY

Independent and dependent events, Introduction to probability. Independent and dependent events. Events compounds. Mutually exclusive events. Rule beyond probability. Probability and combinatory, permutations and combinations. Using Combinatory to solve issues in probability. Statistical studies descriptive statistics Measures of central tendency and dispersion. Average, median, mode, variance and standard deviation. Variables and Distributions of random probability. Random variables. Expected value. Probability distributions (both discrete and continuous). Binomial distribution. Poisson processes. The assembly of a regression line of dots. Linear regression. R-squared. Inferential statistics Making inferences based on sample data. Confidence intervals. The margin of error. Hypothesis testing.

Toyota [3] defines MOOC as online platforms that distribute traditional university courses over the Internet. The success of MOOCS relates to the popularization of online courses. As observed by Mallard [4] and Ribeiro [5] the use of videos on the Internet to support the learning process is a definite trend and is increasingly growing in Brazil.

Courses in MOOC supposedly represent high-quality education. The source of the content and exercises coming from famous and respectable universities give respect to these courses. We suppose statistical, and math content presented in these courses are reliable and uptodate. Learning objects available on MOOCs should have quality and include scientific examples with valuable science data.

\section{TABLE III: MOOCS FOR STATISTICS COURSES}

\section{UDACITY}

Intro to Statistics

Intro to Descriptive Statistics

Intro to Inferential Statistics

Data Analysis with R

\section{COURSERA}

Become a Social Scientist: Methods and Statistics

Reasoning, Data Analysis, and Writing

Johns Hopkins University - Statistical Inference

University of Amsterdam - Descriptive Statistics

University of Amsterdam - Inferential Statistics

Duke University - Data Analysis and Statistical Inference

Princeton University - Statistics One

Johns Hopkins University - Statistics for Genomic Data Science

University of Zurich - Introduction to Statistics for the Social

Sciences

Duke University - Teaching Statistical Thinking: Descriptive

Statistics

University of Houston System - Preparing for the AP* Statistics

Exam

University of Toronto - Statistics: Making Sense of Data

Wesleyan University - Passion Driven Statistics

Johns Hopkins University - Regression Models

The Ohio State University - Applied Regression Analysis

Johns Hopkins University - Data Analysis

Johns Hopkins University - Exploratory Data Analysis

University of Washington - Introduction to Data Science

University of Pennsylvania - Probability

\section{SAYLOR.ORG}

Introduction to Statistics - 93 horas

Advanced Statistics - 96 horas

\section{EDX}

UC Berkeley - Introduction to Statistics: Descriptive Statistics

UC Berkeley - Introduction to Statistics: Inference

UC Berkeley - Introduction to Statistics: Probability

Notre Dame - Heart Stats: Learning to Love Statistics

Harvard - Statistics and R for the Life Sciences

KIExploR - Explore Statistics with R

Harvard - Advanced Statistics for the Life Sciences

UTAustin - Foundations of Data Analysis

\section{TAREA PLUS}

Probabilidad y Estadística - Curso

Estadística para investigadores - Curso

Estadística con profesor10demates - Curso

Curso Práctico de Bioestadística con R - Curso

\section{MIRÍADA X}

Universidad Politécnica de Cartagena - Estadística descriptiva Universidad Politécnica de Cartagena - Probabilidad básica

Universidad Politécnica de Cartagena - AprendeR: Introducción al tratamiento de datos con $\mathrm{R}$

\section{VEDUCA}

Berkeley - Estatística Básica

Berkeley - Probabilidade e Estatística para Negócios

UCLA - Probabilidade para Ciências Médicas

USP - Probabilidade \& Estatística

Source: Udacity [8], Coursera [9], Saylor.Org [10], EDX [11],

Tarea Plus [12], MiriadaX [13], Veduca [14] 
The Internet in the traditional way permits all population to have contact with the top content from respected universities researchers.

The present web-based exploratory study identifies eight major massive online courses website that can assist the professors of statistics in their classes. These eight websites that provide statistical MOOCs are Udacity, Coursera, Saylor.Org, EDX and Khan Academy, with courses in English. Tarea and Myriad Plus X, in Spanish and Veduca in Portuguese. All eight websites and their URL are in Table I.

Table III presents the main statistics courses found in research on the internet.

There are several online courses available in MOOCS intended to statistical education. The main premise of this study is that statistical professors should use these courses as external links in their virtual learning environments.

Links for MOOCs help students to seek more information on the content studied, and boost the learning process through other practical statistical examples, specially designed in the format of multimedia materials.

The courses are available from Udacity, Coursera, EDX, Saylor.Org, Tarea Plus, Myriad X and Veduca. Most courses are available in the English language, but we also found content in Spanish and Portuguese. The fact that most of the MOOCs are in English could be a problem for students that do not have English as the main language. It is a feature that hinders student access to MOOCs. The trend is that massive courses are subtitled and/or translated, and therefore, will not be a problem for foreign students.

Khan Academy is another helpful online system to give significant support to statistical teaching. The Khan Academy is an educational company with a mission to provide online education through a free collection of over 3,800 videos in various areas of knowledge. In Brazil, the Khan Academy videos are translated into Portuguese by the Lehmann Foundation and serve as a teaching tool in schools to teach math content [6]. The Lemann Foundation offers a free program that takes Khan Academy to public schools, training teachers to use the platform with the students, and share that knowledge with other educators [7]. In terms of statistics content, the Khan Academy website offers a variety of subjects that help the student to have their basic training statistics. Table II presents the main statistical content available on the Khan Academy, which can be used to professors in the format of links inside the VLE.

\section{SURVEY WITH STUDENTS - RESULTS AND DISCUSSION}

The case of study had a VLE available to 165 students with external links to objects online, 141 students returned the questionnaire. The four-point scale variables measured in the survey are in Table IV.

The first question asked what the level of VLE usage was during the statistics course. We observed that the students had a high degree of system use. This particular variable means that the VLE had reasonable acceptance by the undergraduates. An analysis of Moodle statistics shows that the VLE level of access could be considered as successful.

The second variable was about video search on the internet. We asked if the student used to explore extra material from other websites on the Web. Results show students not commonly looked for extra material outside the VLE. The students tend to concentrate their efforts in the professor VLE given material. The same situation occurred with Internet videos on YouTube, Vimeo or other sites. We expected a higher level of search for videos, but the opposite was found

TABLE IV: VARIABLES IN THE SURVEY

\begin{tabular}{|c|c|}
\hline V1 & $\begin{array}{l}\text { Level of VLE Use: "What was your level of AVA use during the } \\
\text { course of Prob. and Statistics." }\end{array}$ \\
\hline V2 & $\begin{array}{l}\text { Extra Internet Material: "Did you use material from the internet, } \\
\text { other sites in addition to teaching in the classroom?" }\end{array}$ \\
\hline V3 & $\begin{array}{l}\text { Internet Videos: "Didi you find and watch videos on the Internet } \\
\text { to supplement teaching in the classroom?" }\end{array}$ \\
\hline V4 & $\begin{array}{l}\text { Motivation to Learn: "Materials available on the Internet or AVA } \\
\text { motivate me to learn more about the content presented in lectures } \\
\text { and in the classroom " }\end{array}$ \\
\hline V5 & $\begin{array}{l}\text { Learning Aid: "Materials available on the Internet or VLE help } \\
\text { me understand more about the classroom content." }\end{array}$ \\
\hline V6 & $\begin{array}{l}\text { VLE Relevance: "I find it important to have materials available } \\
\text { on the Internet or VLE to complete the classroom content." }\end{array}$ \\
\hline V7 & $\begin{array}{l}\text { Performance Improve: "My performance in learning the concepts } \\
\text { of this discipline was better due to having materials available on } \\
\text { the Internet or VLE to complete classroom content." }\end{array}$ \\
\hline
\end{tabular}

We also inquired about motivation. We asked if the materials available on the VLE were an instrument of motivation to the student. The majority of the students have more motivation to learn about the data content in the classroom after using the VLE.

Regarding VLE assistance in the learning process, most of the students think materials available online help them to understand more about the statistical content seen in class.

Students also consider important to have materials available on the VLE to complete the given classroom content area. They assess as better the learning performance of statistical concepts if they can find extra material available on the VLE to complement lectures content. Table V presents the variables mean and standard deviation.

TABLE V: VARIABLES MEAN AND STANDARD DEVIATION

\begin{tabular}{lll}
\hline \hline & Mean & St. Dev. \\
\hline V1 Level of VLE Use & 3.15 & .632 \\
V2 Extra Internet Material & 2.38 & .875 \\
V3 Internet Videos & 2.28 & .972 \\
V4 Motivation to Learn & 3.21 & .655 \\
V5 Learning Aid & 3.55 & .638 \\
V6 VLE Relevance & 3.82 & .436 \\
V7 Performance Improve & 3.41 & .633 \\
\hline \hline
\end{tabular}

\begin{tabular}{|c|c|c|c|c|c|c|}
\hline & V1 & & & & & \\
\hline $\mathrm{V} 2$ & $.169^{*}$ & $\mathrm{~V} 2$ & & & & \\
\hline V3 & .130 & $.633^{* *}$ & V3 & & & \\
\hline V4 & .075 & .099 & .123 & V4 & & \\
\hline V5 & .134 & .065 & .054 & $.422 * *$ & V5 & \\
\hline V6 & .071 & .026 & -.018 & $.182 *$ & $.351 * *$ & V6 \\
\hline V7 & $.239 * *$ & -.049 & -.105 & $.426^{* *}$ & $.377 * *$ & $.292 * *$ \\
\hline
\end{tabular}

In Table VI, we present values of all bivariate Pearson Correlation between the seven variables, with respective significance marked. Results show that students who think extra internet material is important, tend to consider the video as the main format. Variables related to the VLE assistance, relevance and performance improve are correlated at the .01 
level, indicating the general importance of the VLE to the learning process. The level of usage has a positive correlation with the performance, pointing out that VLE is important to help students learn the content.

In the survey and informal interviews, we requested suggestions from the students to perceive ideas to increase the potential and usage of the VLE in the statistic course.

The first suggestion regards the calculations. It is important to show how statistical calculations are done. This explanation can help future studies. The explanation of results and solving exercises should be detailed. Detail legend in formulas is crucial to assist schooling of each specific statistical content.

Learners see the professor as the main VLE content supplier. The teacher should provide a broad range of more complex subjects' videos. Self-videos of lectures is also suggested, available on YouTube, as the same pattern as Khan Academy. The professor should publish links to various contents such as scientific articles, to statistical data websites, and video documentaries, with subjects of each topic separately. Each content should have more practical exercises.

Finally, there were some suggestions about the VLE performance. The institution should be aware to improve the performance of the VLE and make it constantly updated. The institution should provide access via smartphone, creating a mobile app, as some desktop VLE files downloaded in pdf do not open in handheld devices.

We requested student feedback about VLE utilization in the statistical course. Some expressions were encouraging and reveal how they feel about the system importance. One student said, "I thought I learned enough in class, but then I realized the material available online helps us a lot." Another student said, "I used VLE a lot. I am sure if the college had this method, requiring students to use VLE on a more often basis, the performance of learning would be better".

Most of the students affirm that the level of VLE depends directly on the motivation to access the system transmitted by the professor in class.

The multimedia VLE content is relevant to students as they can watch videos with other explanations and complementary works. As said by one student "online material improved the understanding of professor lecture... my classmates should have the attitude to seek materials online to understand better the subject studied".

\section{CONCLUSION}

The use of a Virtual Learning Environment reduces the distance between teachers and students and should be used to provide online materials and external links for students to supplement lessons learned in the classroom. The massive courses called MOOCs are relevant courses because they came from traditional high-quality institutions, with competence in scientific research. These MOOCs should be used as a complement to a traditional college education. This paper presents some massive courses that can help the professor of statistics to combine distance and traditional learning using a virtual environment. An exploratory survey of students made at the end of statistic courses shows that students consider the use of VLE relevant for the learning process in higher education.

\section{REFERENCES}

[1] P. Chin, Virtual Learning Environments: Advice on Choosing a VLE, University of Liverpool, February 2005.

[2] P. Ernesto, "Las online communities ganan them lessons y llegan a la company," 2012.

[3] T. Jessica, "Institutional design," What Are MOOCs? 2013.

[4] M. Romain. The revolution of the videos in e-Learning. (2011). [Online]. Availale: http://www.cmconsultoria.com.br/vercmnews.php?codigo $=49337$

[5] R. S. Almeida. What is web 3.0? [Online]. Available: www.publico.pt/tecnologia/noticia/o-que-ea-web-30-1389325

[6] Khan Academy. Website Khan Academy. (2015). [Online]. Available: http://www.khanacademy.org

[7] L. Fundação. A revolução do aprendizado com apenas uma fórmula [Online]. Available: http://www.fundacaolemann.org.br

[8] Udacity. Website Udacity. (2015). [Online]. Available: https://www.udacity.com/

[9] Coursera. (2015). Website Coursera. [Online]. Available: https://www.coursera.org/

[10] Saylor.Org. (2015). Website Saylor Org. [Online]. Available at http://www. saylor.org/

[11] Edx. (2015). Website Edx. [Online]. Available: https://www.edx.org/

[12] Tarea Plus. (2015). Website tarea plus. [Online]. Available: http://www .tareasplus.com/

[13] Myriad. (2015). Myriad X website. [Online]. Available: https://www .miriadax.net/

[14] Veduca Website. (2015). [Online]. Available: http: //www.veduca.com.br/

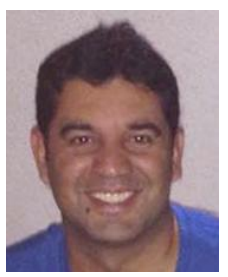

Silvio Carvalho Neto was born on January 20, 1976 in Brazil. He got his doctor of sciences in management from the University of São Paulo (Brazil), MBA at FGV-Fundação Getúlio Vargas (Brazil), and the post-doctoral at Stanford University (USA). He is currently a professor and the dean of Research and Graduate Studies at Centro Universitário Municipal de Franca and a professor at the Technology College FATEC Franca, in São Paulo State, Brazil. His works are in the field of information systems and education, acting mainly on the topics virtual learning environments and online publishing systems. 